\title{
Judicial Perceptions of Media Portrayals of Offenders with High Functioning Autistic Spectrum Disorders
}

\author{
Colleen M. Berryessa*
}

\author{
Stanford University, Center for Biomedical Ethics, 1215A Welch Road Stanford, CA 94305, USA
}

\begin{abstract}
In recent years, sensational media reporting focusing on crimes committed by those diagnosed with or thought to have High Functioning Autistic Spectrum Disorders (hfASDs) has caused societal speculation that there is a link between the disorder and violent criminality. No research exists on how and if the judiciary understands and is affected by this coverage. Therefore this study aims to examine how judges perceive and are influenced by media attention surrounding hfASDs and criminality. Semi-structured interviews were conducted with 21 California Superior Court Judges, including questions on media portrayal. Judges perceived general media portrayals of hfASDs in both positive and negative ways. However, almost all judges who had experienced media coverage surrounding hfASDs and criminality identified it as misleading and harmful to public perceptions of the disorder. These findings suggest judges are not exempt from media attention surrounding violence and hfASDs, and they recognize the potential adverse effects of this negative coverage. Although judges' report their opinions are not affected, the results demonstrate that judges are worried that the public and potentially other criminal justice actors are adversely affected and will continue to be moving forward.
\end{abstract}

Keywords: Criminal Offenders, High Functioning Autistic Spectrum Disorders, Media Portrayal, Asperger's Syndrome, Judges, Sandy Hook.

\section{INTRODUCTION}

In general, commonly held assumptions with regards to Autistic Spectrum Disorders (ASDs) are formulated through exposure to factual and fictional film, television, radio, and written media portrayals of the disorder, such as the movie Rain Man (1988) or Stieg Larsson's The Girl With the Dragon Tattoo series (Browning and Caulfield 2011). Although many of these media portrayals have been positive and have assisted in creating societal awareness and considerations about ASDs, social misunderstandings and inaccurate perceptions of ASDs still very much exist and are only further engendered by dramatic and sensational reporting of occasional acts of violence or criminality by individuals diagnosed with or thought to have ASDs (Howlin 2004). Indeed, in recent years, heightened media attention on lurid crimes committed by offenders diagnosed with or thought to have ASDs, especially individuals with High Functioning Autistic Spectrum Disorders (hfASDs) or with what is commonly known as Asperger's Syndrome, ${ }^{1}$ has led to commonly held assumptions that individuals with these disorders have an increased likelihood of criminality or violent offending because of the their diagnoses or presence of their disorder (Howlin 2004: 300).

Examples of this sensational coverage can be seen throughout mass media, especially in the recent

*Address correspondence to this author at the Stanford University, Center for Biomedical Ethics, 1215A Welch Road Stanford, CA 94305, USA; Tel: 1-650736-0954; Fax: 1-650-723-6131; E-mail: cmberry@stanford.edu

E-ISSN: 1929-4409/14 aftermath of the shootings in Aurora, Colorado and Newtown, Connecticut. ${ }^{2}$ After the shooting in Aurora, Colorado, MSNBC's Joe Scarborough commented that individuals like the shooter in that incident are "somewhere, I believe, on the Autism scale" and although he did not know if this perpetrator had been diagnosed with the disorder, "it happens more often than not" (Alvarez 2012). Following the shooting in

${ }^{1}$ While not explicitly defined as a singular recognizable diagnosis in the Diagnostic and Statistical Manual of Mental Disorders (DSM-5), the term hfASDs is applied to individuals diagnosed with an Autistic Spectrum Disorder (ASD) that have no intellectual or language disability and are seen as cognitively "normal functioning." The syndrome is defined by features such as social naivety, narrow interests or obsessions, compulsive focus on routine, and motor clumsiness (American Psychiatric Association 2013). Recent revisions to the DSM-5 have removed the separate diagnostic category of Asperger's Syndrome and combined four separate Pervasive Developmental Disorders (PDDs) into the umbrella category of ASD (American Psychiatric Association 2013). The total overlap of symptomatic features between hfASDs and Asperger's Syndrome has been questioned for years, with some researchers drawing specific and distinctive differences between the two and others interchanging the terms. For purposes of this paper, and due to the elimination of Asperger's Syndrome in the DSM-5, the terms hfASD refers to individuals who would have been historically diagnosed with Asperger's Syndrome (Klin 2006).

${ }^{2}$ On July 20, 2012, a man named James Holmes perpetrated a mass shooting in a movie theater in Aurora, Colorado during a midnight viewing of the movie The Dark Knight Rises. The suspect used multiple firearms to kill 12 individuals and injure 70 others (for more information on the Aurora, Colorado shooting, please see Frosch and Johnson 2012). On December 14, 2012, a man named Adam Lanza entered Sandy Hook Elementary School in Newtown, Connecticut and fatally shot 26 individuals, including 20 children, with multiple firearms (for more information on the Sandy Hook shooting in Newtown, Connecticut, please see Barron 2012). After both events, heavy media attention speculated on the possibility that the respective shooters both suffered from some form of an Autistic Spectrum Disorder and their disorders contributed to or resulted in their violent actions, even though at the time, there were no confirmed reports of either individual's diagnosis. In 2013, a report by the Connecticut state's attorney (Sedensky 2013) finally confirmed Adam Lanza had been diagnosed in 2005 with a Pervasive Developmental Disorder (PDD) that consisted of Asperger's Syndrome characteristics. The connection between Autistic Spectrum Disorders and violence has been something commonly discussed surrounding mass shootings in recent years (Wachtel and Shorter 2013). 
Newtown, Connecticut, a psychiatrist appearing on Fox News said, regarding that shooter, "He is out of touch with reality. If he had Asperger's, he may have had ongoing meltdowns associated with violent behavior. It is possible he was on medication, and it was not working, and he didn't have empathy and had social problems" (Christopher 2012). Further, recent speculative headlines such as "Expert says Norway killer has Asperger's, Tourette's syndromes" (Agence France-Presse 2012) or "Relative Says Virginia Tech Shooter Was Autistic" (Associated Press 2007) insinuate that having these disorders somehow causes or correlates to the commission of a perpetrator's criminal actions, creating immensely damaging perceptions of those with ASDs.

Although there is inadequate literature on offenders with hfASDs and other ASDs compared to other mental disorders, media reporting on the perceived link between these disorders and criminality has been further fueled by academic studies and reports over the last few decades that have reported a speculative association between the two. In the late 1980s, several clinical case studies reported on the offending and violence history of specific patients with hfASDs in secure settings. These studies concluded that deficient empathy may be the main factor underlying violent behavior by those with hfASDs, and a relationship between hfASDs and violence was more common than previously assumed (Mawson et al. 1985; BaronCohen, 1988). There have also been several other forensic-setting case histories that have connected offending behavior to characteristics of the disorder, such as social naivety and issues with impulse control (e.g. Everall and Lecouter 1990; Tantam 1991; Chesterman and Rutter 1993; Murrie et al. 2002; BarryWalsh and Mullen 2004). Further, several academic studies (Scragg and Shah 1994; Hare et al. 1999; Siponmaa et al. 2001) on the prevalence of offenders with hfASDs in forensic or secure settings concluded the prevalence rate of hfASDs and other ASDs within forensic settings is at least three times that of the general population (estimated 0.36 percent: Ehlers and Gillberg 1993).

Although these studies have suggested a link between offending and hfASDs and other ASDs, other academic reports (e.g. Wing 1981; Ghaziuddin, Tsai, and Ghaziuddin 1991; Wing 1997; Murphy 2003; Myers 2004; Mourisden et al. 2008) have argued that there is no significant evidence to support an association between hfASDs and criminality, and very few of those with hfASDs commit illegal acts. For example, two community studies focusing on offending rates of those with ASDs compared to their non-ASD counterparts concluded individuals with ASDs had a lower likelihood to offend (Woodbury-Smith et al. 2006) and there was no significant association between the disorder and offending (Allen et al. 2008). Additionally several of the original prevalence studies (Scragg and Shah 1994; Hare et al. 1999) have been criticized for selection and sample bias, inconsistent methodological and diagnostic methods, and not properly acknowledging the possible comorbidity of other psychiatric disorders with hfASDs in research samples (Ghaziuddin 1991; Haskins and Silva 2006; Allen et al. 2008; Browning and Caulfield 2011). Therefore, although individuals with mental health disabilities are over-represented in the criminal justice system (Mayes 2003), the overall body of research in this area demonstrates both academic disagreement and insufficient evidence to corroborateany connection between hfASDs and criminality, especially concerning acts of violence (Murrie et al. 2002; Howlin 2004; Browning and Caulfield 2011).

Nonetheless, insufficient academic evidence has not prevented the mass media from reporting criminal or violent acts committed by those diagnosed or thought to have hfASDs in a sensational manner, as well as suggesting that an association between violence and the disorder exists. This type of media reporting creates an inaccurate and negative portrayal of individuals with hfASDs and their likelihood to commit acts of violence or be a danger to society (Allen et al. 2008; Howlin 2004). Unfortunately there is little academic literature on media reporting of criminal offenders with hfASDs or other ASDs. Howlin (2004) argued that by focusing on a very small number of highly publicized cases, sensational media reports are the ones responsible for any perceived connection between ASDs and criminal behavior. Allen et al. (2008) agreed that any speculated link between hfASDs and criminal offending is heavily influenced by the dramatic way in which certain cases have been reported in and by the media. Gunasekaran and Chaplin (2012) cited that media reporting often insinuates that notorious or lurid crimes by those with ASDs are perpetrated due to the disorder without any other information to support that conjecture; often crimes are reported in a fashion that makes it seem that a person must be "mentally unwell" or autistic to have committed the crimes (Gunasekaren and Chaplin 2012; Wessley 2012).

Although there is a dearth of academic literature on specific media reporting of criminal offenders with 
hfASDs or other ASDs, there is a large body of academic literature on how the media generally portrays mentally disordered individuals and criminality, as well as how these portrayals affect and reinforce the traditional social stigmas associated with mental disorders and societal perceptions of mentally disordered individuals and criminal offending. Modern notions of social stigmatization stem largely from the work of Erving Goffman, who described mental illness or disorders as one of the most damaging and harmful of all stigmas as it reduces an individual from a whole person to amalgamation of negative attributes (Goffman 1959; Goffman 1986). Research has shown this negative stigma has visibly affected the attitudes of the general public surrounding the mentally disordered (e.g. Harris 1996; Crisp et. al 2000; Barnhardt 2003), with one of the main sources of stigmatization being portrayals in media (Robert Wood Johnson Foundation 1990). Although sometimes portraying positive characteristics, research has shown that both entertainment and news media far more often portray mentally ill or disordered individuals as violent, threatening and dangerous (Signorielli 1989; Diefenbach 1997; Wilson et al. 2000; Wahl 2003). Newspapers are much more likely to report sensational stories on mentally disordered individuals that are violent, criminal, dangerous, and unpredictable than nonthreatening or sympathetic (Day and Page 1986; Shain and Phillips 1991; Mental Health America 1999) and focus on the killing or victimization of innocent stranger victims by mentally disordered individuals, which makes these rare events of violence seem much more characteristic of those with mental illnesses than they really are (Wahl 1997: 70,84). Wahl (1997: 75,84) concluded these negative media portrayals create an overwhelming sense of fear in the public of those with mental illness and produce an inaccurate societal perception that the commission of violence is directly connected to an individual's psychiatric diagnosis (Gerbner 1980). Overall, research has shown that the media's portrayal of criminality and mentally disordered offenders is predominately negative and does in fact have an influence on how the public views mentally disordered individuals and their likeliness to be a danger to society (Institute of Medicine 2006).

Thus, the ways in which the media stigmatizes and portrays violence, criminality, and mental disordered individuals, including individuals and criminal offenders with hfASDs and other ASDs, impacts the ways in which society understands, perceives, and reacts to the disorders and those diagnosed with them. This stigma may not affect only the general public's view, but also the views of those individuals within the criminal justice system who handle and process these offenders, including judges. Although no studies exist on judges and hfASDs specifically, multiple levels of the criminal justice system, including the judiciary, have been shown to be impacted by stigma against the mentally disordered, making it very difficult for defendants with mental disabilities to be viewed in any way but a negative light when they enter the criminal justice system (Watson et al. 2001; Corrigan 2004; Parry 2005). Judges, who in large are not experts on these disorders but might encounter and handle diagnosed individuals in the courtroom and the larger justice system, often base their opinions regarding the mentally disordered predominantly upon stereotype, self-interests and their own values and biases, a process defined as pretextual decision-making (Perlin and Gould 1995). Parry (2005) commented that pretextual decision-making of judges surrounding the mentally disordered is a direct result of society's flawed views about the relationship between violence and mental disorders. Thus, judges are very much like the general public, in that they frequently let their own beliefs, values and biases direct their perceptions and decision-making (Perlin and Gould 1995; Parry 2005).

While there has been research on the media's impact on the general public, there has been hardly any literature on how judges perceive or are impacted by the media. Since judges have been shown to let their own biases and values influence their opinions, especially regarding the mentally disordered (Perlin and Gould 1995; Parry 2005), as well as make many of the same systematic errors in decision-making and judgment as those made by the general public (Guthrie, Rachlinski, and Wistrich 2000), one could assume that like the general public, judges are also not immune to the influence of the media in their perceptions and decision-making. If so, negative media portrayals of the mentally disordered, including those with hfASDs, and criminality in the media may affect and reinforce the traditional stigmas and stereo types upon which judges have often been shown to base their opinions and decisions in the courtroom (Perlin and Gould 1995; Parry 2005). This is important because the judiciary is traditionally the group of decision-makers who control the responsibility determination and sentencing of an offender, as well as the group that acts as the gatekeepers of what evidence and testimony are presented in the 
courtroom. Further, the judiciary has the ability to write and influence policies and opinions that can affect the decisions and views of other judges, juries, attorneys, other criminal justice actors and the general public. Thus, judges have a substantial amount of influence and power (Stewart 2003), not only over the freedom and future of defendants in their courtrooms, including those who are mentally disordered, but also over the views and opinions of the public and other individuals in the criminal justice system. It is therefore integral to understand how judges perceive media attention surrounding offenders with hfASDs and other ASDs, how they believe their perceptions and decisions are affected by portrayals of the disorders and diagnosed offenders, and if and how judges' believe others within the criminal justice system and public might be influenced or affected by the media.

In light of this literature and heightened sensational media coverage of offenders with hfASDs and other ASDs, paired with judicial power and influence, this current study aims to explore judges' views of how the media portrays hfASDs specifically (rather than other ASDs) and offenders with hfASDs. Interviews were conducted with California Superior Court Judges $(n=21)$. To my knowledge, no studies of this nature exist. Studies that examine judicial experiences in interview contexts are uncommon (Artis 2004) and studies of this nature provide a comprehensive account of judicial perceptions, motivations, and decisionmaking (e.g. Gaylin 1974; Daly 1987; Ulmer 1994; Artis 2004). In what follows, I first discuss the methods and procedure by which these interviews were conducted and analyzed. Drawing on these interviews, I then examine and analyze several themes that emerged, including judges' perceptions of how the media portrays the disorder in both a general context as well as related to criminality. Additionally, with the heavy media attention surrounding the Newtown, Connecticut incident, ${ }^{3}$ the judges were also asked to relate if and how the media coverage surrounding that event changed or affected both their personal as well as the public's views of hfASDs.

\footnotetext{
${ }^{3}$ In the case of Adam Lanza and the Sandy Hook Elementary Shooting in Newtown, Connecticut in December 2012, there was an especially large amount of media attention surrounding the connection between his violent actions and his possible diagnosis with Asperger's Syndrome. This sensational media attention and speculation perpetuating the link between Asperger's Syndrome, Autism and violence resulted in backlash from psychiatric experts, advocacy groups and other individuals within the Autism or Asperger's community, many who spoke out against the skewed and misleading reporting on these issues in relation to the Sandy Hook incident (e.g. Associated Press 2012; Rodriguez 2012; Lutz 2012; Rochman 2012; Plank 2012; Nano 2012).
}

\section{METHODS}

\section{Procedure}

Data reported here were collected during 21 semistructured telephone interviews with California Superior Court Judges from April 2013 to July 2013 as part of a larger mixed methods study of how judges perceive and make decisions concerning offenders with hfASDs on a variety of issues, ranging from responsibility and sentencing to assessing dangerousness, stigmatization in and out of the courtroom, and how the genetic origin of the disorder might affect judicial decision-making. This larger project consisted of a case-study survey and short telephone interviews. Recruitment of judges for interview participation occurred if they volunteered permission in their survey response to be contacted for an interview.

The survey used in the larger project was a structured case-study on an offender diagnosed with an hfASD and asked judges to indicate how they would sentence the offender, what aspects of the disorder and testimony concerning the disorder affected their decisions, and some more general thoughts on hfASDs in the criminal justice system. Of the 1,500 California Superior Court Judges eligible, a random sample of 500 was sent surveys by mail. Mailings included the survey instrument, a cover letter explaining the purpose and goals of the study, and postage to return the survey. Judges were also asked to indicate on the returned survey if they would be willing to participate in a follow-up telephone interview, and if so, provide contact information. Sixty-one judges returned surveys and 22 judges elected to be re-contacted for the telephone interviews included in this analysis.

Using the contact information provided by the judges on the survey, I contacted the judges between 1-5 times, and scheduled a time to interview the judge based on convenience for the judges' schedules. Twenty-one judges were interviewed out of the 22 who elected to participate on their returned survey; one judge could not be reached. The Stanford University Institutional Review Board approved this study, and all participants gave their informed consent to participate and to be audio-recorded. All interviews were recorded with consent from participants, transcribed, and no financial compensation was provided for participation. Interviews averaged 25 minutes.

As the interview participants for this study were drawn from survey respondents, it is important to note 
limitations of this research, focusing on the low response rate of the survey. First, an inherent weakness of the analysis and conclusions of this research is that they are based on a small sample. Yet, it is integral to convey that a response rate of this size is not unusual for surveys targeted at the judiciary, who are notorious for not returning surveys (Robinson 2012). The judiciary has been traditionally labeled by researchers as a difficult and unreceptive population, as well as a "hard to reach group" (Cowan et al. 2006: 548), concerning participation in social science research (Dobbin et al. 2001; Darbyshire 2011). Therefore although the response rates for the survey and consequently the interviews are low, they are characteristic of other judicial studies. Although no statistical significance can be drawn from the small sample, the interviews can be used to shed light on judicial perceptions, attitudes and decision-making.

Second, a mail survey was used to contact a representative sample of participants, rather than a web-based or telephone survey. Surveys by mail have often been shown to result in very low response rates (Yu and Cooper 1983) and single figure response rates are common in industrial mail surveys (Thompson 1984). As the target population of the survey was California Superior Court judges, the only publically available contact information for this population was a listing of courthouse mailing addresses provided by the California Superior Court website. Therefore, a mailing was the only option for the survey, rather than a telephone or web-based survey that in some cases have produced higher response rates (e.g. Guterbock et al. 2000; Baruch, Yehuda, and Holtom 2008). Nonetheless, efforts were made to bolster responses, following traditional methods aimed to increase response rates (Kanuk and Berenson 1975). Judges were guaranteed that their individual responses would be confidential and that results would only be shared in the aggregate. Personalized cover letters were included in each mailing and return self-addressed envelopes and postage for completed surveys were included. A local judge, who approved of my materials and methods, was consulted before the mailings to comment on the length, structure, and content of the survey and cover letter.

Finally, the low survey response rate raises the possibility of bias in the interview responses directly related to the purpose of the research (Fowler 2009). Individuals who respond to mail surveys often have a specific interest in the subject matter of the survey (Whitehead 1991). In this case, it is likely that judges who had an interest or were personally affected by Autism or mental health issues would be more likely to respond to the survey than other judges. It could be argued that opinions of those judges, who volunteered to be interviewed and were interested enough in the project to return the survey and agreed to give up 20 to 25 minutes of their time, might be different than those in the larger population or other survey respondents who did not volunteer to be interviewed. Therefore, I cannot generalize these findings to the experiences or views of all California Superior Court Judges.

\section{The Interview Guide}

The interview guide was a set of 20 semi-structured questions, broken into three major topics: (1) questions about genetics and genetic disorders, both generally and in specific relation to criminal offenders and the courtroom; (2) ASDs and hfASDs, both generally and in relation to criminal offenders and the courtroom; and (3) personal experiences with and media portrayal of hfASDs and genetics, both generally and in a criminal justice context. The questions relevant to this paper concerned media portrayal of hfASDs in both a general and criminal justice context. Sample questions included the following: In your opinion, how does the media usually portray Autistic Spectrum Disorders or Asperger's Syndrome? What has shaped your view of Asperger's Syndrome or other Autistic Spectrum Disorders when it comes to criminal offenders, the legal or the criminal justice systems? How did the Sandy Hook Elementary School tragedy and its aftermath, or other media stories in the last 1-2 years, change or affect your views on High Functioning Autistic Spectrum Disorders or Asperger's Syndrome? The interviews began with preliminary information about the interview and project. Consent for participation and recording was gathered for each participant. The questions and information asked in the telephone interviews stand-alone from the case-study survey and information collected in the interviews was not based upon on the judges' survey answers.

\section{Coding and Analysis of Interview Responses}

Interview transcripts were imported into NVivo 10 (QSR International 2012) for qualitative coding. The coding scheme was developed through an open coding of a subset of 10 interviews to identify emergent themes using a constant comparative analytic approach, following an iterative and inductive coding process for analysis (see Glaser and Strauss 1967 and Strauss and Corbin 1990). All interviews were coded in 
their entirety by a single coder (CB). A random selection of interviews $(n=6,28 \%)$ was chosen for cocoding by a second independent coder to validate the coding scheme. Co-coding confirmed a high chancecorrected agreement between coders (Cohen Kappa = .89). Concerning this analysis, the codebook provided clearly articulated instructions for coding responses related to media portrayal of ASDs and hfASDs. Responses were assessed against the codebook criteria and then coded as either "media portrayal" or "Sandy Hook." In order to be coded as "Sandy Hook," the judge had to refer to how the media portrayed ASDs, Asperger's Syndrome, or related concepts concerning the incident in Newtown, Connecticut, or how the media has affected the public's or judges' own views on the subject.

\section{RESULTS}

\section{Respondents' Characteristics}

Out of 61 judges who responded to our larger casestudy survey, 22 judges elected to participate in interviews (one judge elected to participate but could not be reached for the interview). A total sample of 21 judges provided data for the current study. A full demographic description of the interview sample is included in Table 1.

\section{Research Findings}

Judges expressed a variety of opinions in the interviews. Below, I separate these opinions into three broad categories: (1) General Media Portrayal of hfASDs; (2) Media Portrayal of hfASDs and Criminality; and (3) Media Portrayal of hfASDs and the Sandy Hook Shooting. I then discuss and give examples of many of the common themes observed within each of these categories, as well as the possible implications of certain research findings.

\section{General Media Portrayal of hfASDs}

Although many judges expressed that the media generally portrays hfASDs in either a positive or negative manner, the widely held sentiment by those interviewed was these portrayals are often a mixture of both good and bad. Those who identified media portrayal as solely positive focused on fictional portrayals of individuals with the disorder as well as how media creates exposure for the disorder to the general public. One judge who identified media portrayal as positive said that her main exposure was from the protagonist in the Girl with the Dragon Tattoo
Table 1: Judicial Interview Participant Demographics

\begin{tabular}{|c|c|}
\hline Characteristic & Number of Participants $(n=21)$ \\
\hline \multicolumn{2}{|l|}{$\underline{\text { Degree }}$} \\
\hline M.A. & 0 \\
\hline J.D. & 21 \\
\hline Ph.D. & 0 \\
\hline L.L.M. & 0 \\
\hline M.D. & 0 \\
\hline M.B.A & 1 \\
\hline \multicolumn{2}{|l|}{ Time on Bench } \\
\hline Less than 1 year & 2 \\
\hline $1-5$ years & 4 \\
\hline $6-10$ years & 7 \\
\hline More than 10 years & 8 \\
\hline \multicolumn{2}{|l|}{ Cases Handled Per Day } \\
\hline 5 or fewer & 5 \\
\hline $11-15$ & 1 \\
\hline $6-10$ & 2 \\
\hline Greater than 15 & 13 \\
\hline \multicolumn{2}{|l|}{$\underline{\text { Age }}$} \\
\hline Less than 30 & 0 \\
\hline $30-39$ & 0 \\
\hline $40-49$ & 1 \\
\hline $50-59$ & 11 \\
\hline $60+$ & 9 \\
\hline \multicolumn{2}{|l|}{$\underline{\text { Gender }}$} \\
\hline Female & 7 \\
\hline Male & 14 \\
\hline
\end{tabular}

series ("I read those and I liked them. They kind of make her heroic figure," adding "that l've heard a lot of positive things about people with Asperger's" (Interview 11)) while another discussed the character Sheldon Cooper from the television show, The Big Bang Theory ("I think he's classic Asperger's, but he makes them more lovable" (Interview 3)).

Other judges who perceived media coverage of the disorder as positive focused on how exposure brings a better understanding and acceptance of the disorder. One said, "I feel like the media has helped a lot in bringing to the popular culture the wide ranging effects of these disorders... there has been a lot more public discussion as a result of various news articles that l've read and seen in the last five or eight years, so I think it's been favorable" (Interview 4). Another commented 
that media reporting on hfASDs and Asperger's Syndrome positively affects understandings of Autism on the whole: "You know, you're hearing more about it, but I think actually the Asperger's helps people understand the Autism. I think people are more accepting of it now" (Interview 5).

Those who discussed media portrayal as negative focused on how the representations of the disorder's characteristics, such as an individual's affect, behavior, and ability to function, are off-putting and adversely affect perceptions of the disorder. One judge said that observing the characteristics of those with hfASDs, without knowing them, could cause prejudgment against both diagnosed individuals and the disorder itself:

"I think that the...sometimes for folks that have an Autistic spectrum disorder, because of their affect and their behavior, oftentimes they don't seem to receive the same level of sympathy and understanding that you might have with somebody that has some other type of a disorder... I think there's a tendency to pre-judge based on affect." (Interview 7)

Another judge was very negative regarding the portrayal of all ASDs, but could not remember specifically seeing those diagnosed as high-functioning or with Asperger's Syndrome in the media:

"I think the media portrays Autistic disorders as people unable to function. And I don't mean, yes they can take in oxygen and eat and drink and their bodily functions can work but they're not...I think the media portrays people with Autism as being very low functioning, unable to live independently people. I think to the extent Asperger's syndrome has been even portrayed in the media, I don't know that I've seen it." (Interview 19)

The majority of judges who commented on media portrayal perceived it as a combination of both negative and positive representations of the disorder. These responses focused on drawing distinctions between negative and positive representations of different topics. For example, one response drew a distinction between types of media, saying that visual media, like movies and television, are negative in their portrayals, while news media, like newspapers and documentaries" tend to be pretty sympathetic" and try "to educate people about all of it" (Interview 10). One judge perceived a major difference between how the media portrays genetic disorders, as negative, ("I think the media tends to sensationalize them, and that's a negative thing. There's nothing positive about seeing, you know, an unappealing photograph of somebody and have them, you know, labeled as being genetically disordered." (Interview 15)) and hfASDs, as more neutral ("I think that Asperger's syndrome doesn't receive the same kind of negative thing. I think people...you know, the media tends to treat that more as scientific information and presents it more neutrally rather than genetic disorder" (Interview 15)).

Conversely, another judge commented that there is not enough distinction drawn in the media. He stated that although he thought the media portrays those with hfASDs in a favorable way, the media tends to equate these individuals to those with more severe developmental disabilities:

"It seems like to me, my impression is the media tends to display individuals with those conditions in a fairly favorable way, although, you know, it's sort in a quaint favorable way, treating many of those people the same as if they're developmentally disabled and not...and I recognize the distinction between someone who has say Asperger's syndrome and someone who is actually developmentally disabled... I think media tends to equate those two things and makes people with those conditions seem more, I don't know, cuddly or something." (Interview 20)

Some judges drew distinctions between modern and past media portrayals of the disorder, such as "I think it's slowly turning to be more of an understanding rather than a stigma. I think people are beginning to pick up more about what that means and there has been more books written about it, more media attention, and I think the general fund of knowledge available for people has become better" yet "I still think there's still kind of a danger zone associated with it" (Interview 18). Another used the movie Rain Man as an example of negative media portrayal but recognized the movie as a turning point: "It's a lot better than when the movie Rain Man came out, which was more than 25 years ago. On the other hand, that film actually advanced the ball considerably from...the situation that 
had existed prior...Autism is discussed in the mainstream press now all the time" (Interview 2).

By and large, the majority of judges conveyed in their responses that general media coverage surrounding hfASDs and individuals with the disorder is both positive and negative. Although judges expressed concerns that the media focuses on the negative characteristics of this disorder and often interchangeably labels those with hfASDs as those with more severe developmental disorders, judges conveyed optimism that the media in recent years has been focusing on exposing and educating the public on the disorder, portraying it in a more accepting and sympathetic manner and fostering public discussion. This recognition and expressed optimism by the judges is encouraging, as positive and educational media representations can help counter the negative stereotypes and biases that the judiciary, as well as members of the general public who might serve on juries or in other criminal justice roles, have often shown to hold toward the mentally disordered, including those with hfASDs. These didactic portrayals can improve perceptions both generally and within criminal justice practice.

\section{Media Portrayal of hfASDs and Criminality}

Although some judges perceived positive representations of hfASDs in the media when they are discussed in a general sense, this was not the case when judges expressed their views of how the media portrays the disorder in relation to criminality or offending behavior. The almost universal response of judges who have seen or experienced media coverage surrounding offending behavior and hfASDs perceived it as negative, misleading, and harmful to all individuals who have been diagnosed with the disorder. Judges voiced concerns that the media can misinform the general public and distort their views of the disorder's connection with violent behavior, with reactions such as "I think there's a chance that certain things the public might make wrong assumptions about how such people are prone to violence." (Interview 16) and "The media really thrives on gossip and unfortunately, I think a lot of people don't recognize that. When you throw out a diagnosis like that, you're really hurting people" (Interview 3). Another commented that "they're [the media] giving someone a...not a path, but giving a reason why the person acted as they did" (Interview 14). Regarding the perpetration of several mass shootings in the last few years, one judge said, "I think that some of the press was trying to just say that it was caused by Asperger's as I recall and that was just absolutely fallacious, but I think that that word got out and I think some people actually believe it" (Interview 18).

There were also several mentions of how the media, in regards to criminal offending, depicts the disorder as a mental disturbance or something that requires institutionalization. One response attributed the media to conflating hfASDs and Asperger's Syndrome with mental illness: "The general public doesn't understand what... those two diagnosis [hfASDs and Asperger's Syndrome] are. That's kind of an odd answer but, yeah, if they get them mixed up, that it means mentally ill, and you're going to be alone or going to shoot people, yeah, it has in fact changed them, but I don't think that's true" (Interview 14). In the same vein, one judge commented on the media's labeling of offenders with hfASDs as odd or disturbed, saying, "it's sort of even this idea of a loner or somebody who's different, isolated socially, thinking secret thoughts and keeping little diaries, and harboring malice and you know, it's portrayed in a negative way" (Interview 15).

Another focused his response on how these offenders are portrayed as if they are too "unwell" to be helped: "they're [offenders with hfASDs] covered from a standpoint that the person is, you know, either not really amenable to treat... of addressing effectively in the criminal justice system, that the person really belongs in some sort of a psychiatric institution" (Interview 8). Further, one judge focused his reaction on coverage of the Virginia Tech Shooting and discussions of that perpetrator's cognitive state or attributes:

"The problem you have, and let's take this after the Virginia Tech shooting, is the number of commentators in the media and elsewhere say why is this kid in school, why is he in college, you know, why wasn't he institutionalized... People show these symptoms all the time. It doesn't mean they're going to go out and kill a bunch of kids. And I think that's one of the problems with the media's... reaction...when someone does something horrible, they focus in on all these issues." (Interview 13)

Only one judge indicated any positive result from media coverage of offenders with hfASDs but focused his response on the media's attention to a wider set of 
offenders with a range of diagnosable mental disorders: "we have these mass shootings which I think with very few exceptions are caused by people who have mental disorders of one kind or another. Now that...I think that is generating a far greater interest by the court system and the participants in the court system as well as the general public to try to do prevention" (Interview 19).

Overall, judges almost universally perceived the portrayal of hfASDs and criminal offending in the media as negative, misrepresentative, and damaging. Interviewed judges do in fact recognize the misleading and harmful bias in this media coverage. The recognition of this bias in the media is potentially beneficial for the judiciary and the entire criminal justice system, in that problems resulting from bias that could potentially affect opinions and decisions in the courtroom might be diminished. By identifying this bias, judges have an opportunity to mitigate it and its affects on their decision-making and opinions regarding offenders who might enter their courtrooms. Judges, emboldened by their influence, also have an opportunity to identify and voice this media bias to other judges, law enforcement, attorneys and other members of the general public in an attempt to prevent it from affecting their attitudes and decisions.

\section{Media Portrayal of hfASDs and the Sandy Hook Shooting}

Judges were also asked, apart from overall reactions to media depictions of hfASDs and criminality, to specifically describe their perceptions of the coverage surrounding the Sandy Hook Shooting in Newtown, Connecticut. These responses focused on how coverage of the Sandy Hook Shooting has affected both the judges' own perceptions as well as how the judges believe it has affected the public's view of hfASDs and a link to violence. Judges said that the media coverage has not affected their personal views, but it has made them think about a variety of issues. Several responses surrounded the concepts of early identification, prevention, and understanding, both in and out of the criminal justice system. Some judges commented on how the coverage has generated thoughts about how families understand and deal with the disorder and how they may fail to recognize it early. One commented that "it absolutely was beyond my comprehension how that family of Mr. Lanza could have ignored or misunderstood the red flags that had been there for years, and why anybody in their right mind would think that the answer is you get that disturbed child a gun and teach them how to shoot at a range" (Interview 4), while a different judge said that although the Sandy Hook shooting "hasn't changed my view, I think there's probably a lot more to it, you know, how the kid was raised and how the mother dealt with the situation more than anything else, and I think a lot of the problem with Autism and stuff is identifying it early and dealing with it because I think a lot of it can be dealt with if treated and addressed earlier in life. You know if you wait too long, it's kind of too late it seems" (Interview 17). Another commented similarly:

“Well, I don't think it's...it's certainly an eye opener but I don't think it's changed the fact that I don't perceive [that] the people in the category you're describing are normally prone to violence, and it certainly has affected my view toward the parents of such a person and how they, you know, should not do the things that this mother did in terms of weapons and all that." (Interview 16)

Numerous other reactions centered upon how the Sandy Hook coverage has made the judges think about the criminal justice system and its understanding and response to offenders with mental health issues and mental health treatment. One judge said the Sandy Hook coverage has made him feel "the need for better understanding by everyone in society, and obviously the courts and the whole entire justice system, all justice partners," adding, "we can't start, you know, creating a stigma for everyone that has, you know, a spectrum disorder, so yeah, no, it's just unfortunately maybe that is the kind of thing which is, you know, making people realize they need to stretch any resources to study and understand the stuff" (Interview 10). To another judge, whose opinions have not been changed by the Sandy Hook coverage, commented that to him it has brought up the "issue of mental [health] treatment. It's rather, you know, preventative, and if he did... of course I don't think he came in contact with the criminal justice system, but it would have been much better. Let's say he had some offense, it would have been better if he got treatment rather than six months in jail. That wouldn't have helped, jail wouldn't have helped" (Interview 5). Other responses echoed these sentiments:

"We need to find a way to address, to identify it much, much earlier, and take the people out of the system to where they could commit a crime like that. And not 
necessarily out of the system from a criminal standpoint, it may be psychiatric commitment or something of that particular nature... Something like that comes up and everybody's surprised, well 'we didn't know he was going to do that.' His mother didn't know he was going to do it, and so until we can identify it earlier and start to address it earlier, it's scary." (Interview 8)

Although a few judges voiced that they did not believe the public's views of hfASDs and offending behavior has changed due to the Sandy Hook media coverage, the majority of judges interviewed believed the public has been affected negatively by the coverage. Many pointed to a creation of fear within society around these issues. One judge even said, "I think that the public's getting scared" (Interview 8). Further, regarding Sandy Hook, this was another response:

"I think it's [the Sandy Hook incident] put fear in a lot of people, you know, and that I don't think that society is able to distinguish between the different illnesses and conditions that affect the mind, and I think that it's created a general fear of anyone that we may think doesn't...is not able to think rationally and so....but I think incidents where, you know, there's been an association with some type of mental health condition has increased the fear, the distrust." (Interview 12)

Others voiced concern that speculation in the media about Autism's role in the crimes committed in Newtown, Connecticut has caused public alarm concerning the disorder itself and all individuals diagnosed with hfASDs, with responses such as, "They [the media] just start speculating. And that is not a good thing for people with Asperger's because if they're speculating he might have Asperger's and people hear that, they will be afraid of people like that, and they won't want their children to play with people who have Asperger's" (Interview 3) and "I mean I know people that jump to conclusions. They hear something like that and they go, oh, well they're all dangerous, you know, or things like that, and nothing can be further from the truth" (Interview 9). Another said, "I try not to watch that stuff... I didn't see it but probably a gazillion million people did, and therefore they learned that if someone has Asperger's they think they're, you know, an inch away of grabbing a gun and killing 26 people. I think that's a negative stigma that is illogical and that the media can perpetrate" (Interview 19).

Finally, one noteworthy response on how the public has been negatively affected by Sandy Hook also provided some recommendations on how law enforcement perceive these offenders and how training might better equip law enforcement in handling these offenders moving forward:

"I think Sandy Hook made people unduly concerned about folks with Autistic Spectrum Disorders and I think that that's unfortunate. When I first read the very first account that came out about that, that was sort of my take on what his issues were even before the press really said much about it, and you know, my husband, who has a law enforcement background, said 'well, you know, I would be surprised if somebody with that diagnosis did that,' and I said, 'oh I wouldn't, under the right circumstances, absolutely,' and so I think, you know, his perception coming from a law enforcement background and mine coming from a judicial background was diametrically opposed. One of the things it sort of made me realize is that it would benefit, and l've considered this to be true and I still consider it to be true, for law enforcement to have more and more frequent training on people with different kinds of mental health diagnoses and different disorders that affect their mood and their affect and that sort of thing because, you know, just like you relate to people that have different levels of emotionality and different ability to communicate, you know, you might deal differently with somebody that has an Autistic Spectrum Disorder diagnosis if you learned, you know, this is how these folks tend to present themselves, these are things...perceived to be threats, these are the best ways to communicate, you know, and I just think it goes back to what I said about information being power...I think there's a lot of unnecessary deaths and unnecessary injuries because people out in the field that are first responders don't often have the tools to be able to recognize what they're seeing and figure 
out the best way to deal with it in what can often be a split second decision making process." (Interview 7)

On the whole, although judges were firm in their beliefs that their attitudes and decisions are not affected by the media coverage surrounding the Sandy Hook shooting, the coverage did seem to affect how judges think about the criminal justice system and its understanding, identification, and response to offenders with mental health issues and mental health treatment. If this sample is any indication, it seems that the Sandy Hook coverage has at least to some degree exposed these issues to members of the criminal justice system, and could potentially create further discussion on what can and should be done regarding the processing of, treatment of and response to offenders with hfASDs and other mental disorders in the criminal justice system. Further, judges vocalized that they believe the Sandy Hook coverage has negatively affected, frightened, and misled the public, especially surrounding the likelihood of violent behavior of individuals with hfASDs. By recognizing that the Sandy Hook coverage has a potential negative influence on the public, judges have an opportunity to voice their concerns surrounding this negative bias to the public and other criminal justice actors.

\section{CONCLUSIONS}

In conclusion, what little academic literature exists agrees that the media tends to sensationalize crimes associated with people with ASDs, and specifically those with hfASDs or Asperger's Syndrome, creating an inaccurate and negative public perception that individuals with hfASDs are more inclined to commit acts of violence or be a danger to society (Howlin 2004; Allen et al. 2008; Gunasekaran and Chaplin 2012). Although some academic research has suggested a link between ASDs, hfASDs and criminality or violent behavior (e.g. Mawson et al. 1985; Baron-Cohen 1988; Scragg and Shah 1994; Hare et al. 1999; Siponmaa et al. 2001), other research has put forth that there is no link between these diagnoses and violent offending and very few individuals with the disorder criminally offend or are violent (e.g. Wing 1981; Ghaziuddin et al. 1991; Wing 1997; Myers 2004; Haskins and Silva 2006; Allen et al. 2008). Although conflicting academic reports provide no solid evidence to link these disorders and violent offending, this does not prevent the media from reporting the crimes committed by those with hfASDs and other ASDs in the same sensational, negative manner in which the media traditionally portrays mentally disordered or ill individuals and criminal behavior, as threatening, dangerous, unpredictable, and predatory. Ultimately the manner in which the media reports crimes by mentally disordered offenders seriously and negatively impacts how all those exposed to this coverage perceive violence, mental illness and mental disorders (Gerbner 1980; Day and Page 1986; Shain and Phillips 1991; Wahl 1997), including hfASDs and other ASDs.

Media coverage not only has the ability to affect the views of the public exposed to these portrayals, but also judges, who as members of the public, might also be subject to error and potential media influence (Guthrie et al. 2000). Judges, in addition to drafting policies and opinions for criminal justice actors as well as other judges, have a huge task of handling offenders throughout the legal process and often have to make difficult decisions such as what evidence is allowed into the courtroom or whether to sentence offenders to prison time or probation. Due to their influence and roles, it is important to study the perceptions, motivations, and decision-making (e.g. Gaylin 1974; Daly 1987; Ulmer 1994; Artis 2004) of members of the judiciary, and in this case, it is integral to understand how judges perceive and are affected by media portrayals of ASDs, hfASDs, and diagnosed offenders. In addition to examining if the media impacts the judiciary's opinions or choices on these issues, it is also key to examine if judges believe the views and decision-making of the public, as potential jury members, or other criminal justice actors are affected as well.

Thus, this study focused on interviews with California Superior Court Judges to survey their perceptions on general media portrayal of hfASDs, media portrayal of hfASDs and criminality, and media portrayal of hfASDs and the Sandy Hook Shooting. These interviews revealed a wide variety of opinions on these areas. Overall, while some judges identified it as either decidedly good or bad, judges primarily perceived the general media portrayal of hfASDs as a mixture of both negative and positive representations. Many of those responses drew distinctions between specific topics or mediums, such as perceived differences in the media portrayal of hfASDs versus genetic disorders, of modern versus past representations, and between visual media, like movies and television, and news media, like newspapers and documentaries. Negative classifications focused on media depictions of the disorder and its symptoms as off-putting, dysfunctional, and disabled and the 
possible harmful stereotypes from these depictions, while positive identifications discussed favorable fictional portrayals of those diagnosed with hfASDs and the media as an educational tool on the disorder for the general public. Ultimately, although judges did voice concerns about the media's negative bias, judges seemed to fully recognize it and expressed support and enthusiasm surrounding positive and educational media representations of the disorder. The use of positive, educational media has the potential to incite public discussion and counteract negative stereotypes and preconceptions towards the mentally disordered.

Almost all judges interviewed who had experienced media coverage surrounding hfASDs and criminal offending identified it as very negative. Judges perceived this coverage as misleading, creating false associations between violent behavior and having the disorder, as well as between being mentally unwell or "sick" and being diagnosed with an hfASD. These findings reflect reporting in literature on the media reporting of criminality and hfASDs (Howlin 2004; Allen et al. 2008; Gunasekaran and Chaplin 2012), as well as more general literature on criminality and mental disorders (e.g. Day and Page 1986; Shain and Phillips 1991; Wahl 1997). This coverage misinforms and distorts the view of the greater public, hurting all individuals in society who have been diagnosed with the disorder. Yet, although these representations are commonplace, the fact that judges recognize the misleading and harmful media reporting surrounding hfASDs and criminal offending does provide an opportunity to prevent it from adversely affecting attitudes and decisions of other judges, criminal justice actors and the general public.

Judges' responses concerning how the coverage around the Sandy Hook Shooting affects both their own perceptions and the public's view of hfASDs and criminality conveyed similar sentiments. Although on the whole judges are not affected by the Sandy Hook coverage, the coverage does inform judges about issues surrounding the disorder and diagnosed offenders in the criminal justice system and could encourage future discussion on how to handle these issues moving forward. The majority of judges believed that the public is negatively affected, with the media coverage creating a fear, distrust and misunderstanding in society of those with the disorder and their potential or likeliness to commit an act like that seen in Newtown. Yet, by recognizing that the Sandy Hook coverage may negatively affect the public, judges once again have an opportunity to vocalize their worries about this negative bias to the public and other criminal justice actors, as well as inhibit it from influencing criminal justice practice.

As previously mentioned, there are several limitations to this dataset. The sample size was small and as such, I cannot generalize these findings to the experiences or views of all California Superior Court Judges. Furthermore, opinions of interview participants, due to their interest in the subject matter, might be different than those in the larger population of California Superior Court Judges or those who did not volunteer to be interviewed. Nonetheless, the findings from these interviews suggest that judges are not immune from exposure to media coverage on these issues, and many take notice on how hfASDs are being portrayed. This is both true in a general sense and when it concerns criminality and other criminal justice issues. Although judges might report they are not affected or base their future decision-making off what is portrayed in the media, they are increasingly concerned that members of the general public are being misled and might jump to the conclusion that not only is there a relationship between ASDs, hfASDs and potential criminality, but also that all individuals with these diagnoses are dangerous and capable of committing violence at any given time. This might not only affect perceptions or the possible decision-making of juries made up of the general public, who could potentially be assigned to a case involving an offender with an ASD or hfASD, but also how law enforcement, attorneys, and other criminal justice actors within society interact with and process these offenders. I, therefore, recommend for future research on the public perceptions, as well as the perceptions of other criminal justice actors, of media portrayals of those with ASDs and hfASDs to gauge if the concerns expressed in these findings are warranted.

\section{ACKNOWLEDGEMENT}

This research was supported by a grant from the National Institute of Health (P50 HG003389-09). Thanks are given to Mildred Cho, the grant investigator, Nanibaa' Garrison, who was instrumental in the development and implementation of this project, and Emily Borgelt, who co-coded interview responses. Finally, I thank the judges who were interviewed for their time and willingness to participate in this research on such an important topic.

\section{REFERENCES}

Agence France-Presse. June 9, 2012."Expert says Norway killer has Asperger's, Tourette's syndromes." News 5 Philippines. 
Retrieved November 3, 2013 (http://www.interaksyon. com/article/34233/expert-says-norway-killer-has- aspergerstourettes-syndromes).

Allen, David, Carys Evans, Andrew Hider, Sarah Hawkins, Helen Peckett, and Hugh Morgan. 2008. "Offending behaviour in adults with Asperger syndrome."Journal of Autism and Developmental Disorders 38(4):48-758 http://dx.doi.org/10.1007/s10803-007-0442-9

Alvarez, Alex. July 23, 2012.“Joe Scarborough: People Like James Holmes May Be 'Somewhere On The Autism Scale." MEDIAite. Retrieved November 3, 2013 (http://www.mediaite.com/tv/joe-scarborough-people-likejames-holmes-may-be- somewhere-on-the-Autism-scale/).

American Psychiatric Association. 2013. Diagnostic and Statistical Manual of Mental Disorders. 5th ed. Arlington, VA: American Psychiatric Publishing.

Artis, Julie E. 2004. "Judging the best interests of the child: Judges' accounts of the tender years doctrine." Law \& Society Review 38.4:769-806. http://dx.doi.org/10.1111/j.0023-9216.2004.00066.x

Associated Press. April 20, 2007."Relative Says Virginia Tech Shooter Was Autistic." Fox News. Retrieved November 3, 2013 (http://www.foxnews.com/story/2007/04/20/relativesaysvirginia-tech-shooter-was- Autistic/).

Associated Press. December 16, 2012. "Experts: No link between Asperger's, violence." USA Today. Retrieved January 12, 2014 (http//www.usatoday.com/story/news/nation/2012/12/16/ sandy-hook-school-shooting-asperger-violence/ 1772589/).

Baron-Cohen, Simon. 1988. "An assessment of violence in a young man with Asperger's syndrome." Journal of Child Psychology and Psychiatry 29.3:351-360. http://dx.doi.org/10.1111/j.1469-7610.1988.tb00723.x

Barron, James. December 14, 2012."Nation reels after gunman massacres 20 children at school in Connecticut." New York Times. Retrieved January 14, 2014 (http://www.nytimes. com/2012/12/15/nyregion/shooting-reported-at-connecticutelementary-school.html?pagewanted=all).

Barry-Walsh, Justin B., and Paul E. Mullen. 2004."Forensic aspects of Asperger's Syndrome.: Journal of Forensic Psychiatry \& Psychology 15.1:96-107.

http://dx.doi.org/10.1080/14789940310001638628

Baruch, Yehuda, and Brooks C. Holtom. 2008. "Survey response rate levels and trends in organizational research." Human Relations 61(8):1139-1160. http://dx.doi.org/10.1177/0018726708094863

Browning, Ann, and Laura Caulfield. 2011."The prevalence and treatment of people with Asperger's Syndrome in the criminal justice system." Criminology and Criminal Justice 11.2:165180 http://dx.doi.org/10.1177/1748895811398455

Chesterman, Paul, and Susan C. Rutter. 1993. "Case report: Asperger's syndrome and sexual offending." The Journal of Forensic Psychiatry 4.3:555-562. http://dx.doi.org/10.1080/09585189308408222

Christopher, Tommy. December 16, 2012. "Fox News And The New York Times Abet Media Effort To Falsely Link Autism With CT Shooting." MEDIAite. Retrieved November 3, 2013 (http://www.mediaite.com/print/fox-news-and-the-new-yorktimes-abet-media-effort-to-falsely-link-Autism-with-ctshooting/).

Crisp, Arthur H., Michael G. Gelder, Susannah Rix, Howard I. Meltzer, and Olwen J. Rowlands. 2000. Stigmatisation of people with mental illnesses. British Journal of Psychiatry 177:4-7.

http://dx.doi.org/10.1192/bjp.177.1.4

Corrigan, Patrick W. 2004. "Target-specific stigma change: a strategy for impacting mental illness stigma." Psychiatric Rehabilitation Journal 28(2):113-121. http://dx.doi.org/10.2975/28.2004.113.121
Cowan, Dave, Sarah Blandy, Emma Hitchings, Caroline Hunter, and Judy Nixon. 2006. "District judges and possession proceedings." Journal of Law and Society 33(4):547-571. http://dx.doi.org/10.1111/j.1467-6478.2006.00370.x

Darbyshire, Penny. 2011. Sitting in judgment: the working lives of judges. Oxford: Hart Publishing.

Daly, Kathleen. 1987. "Structure and practice of familial-based justice in a criminal court." Law and Society Review 21(2):267-290. http://dx.doi.org/10.2307/3053522

Day, David M., and Stewart Page. 1986. "Portrayal of mental illness in Canadian newspapers." The Canadian Journal of Psychiatry 31(9):813-817.

Diefenbach, Donald L. 1997. The portrayal of mental illness on prime-time television. Journal of Community Psychology 25(3):289-302.

http://dx.doi.org/10.1002/(SICl)15206629(199705)25:3<289::AID-JCOP5>3.0.CO;2-R

Dobbin, Shirley A., Sophia I. Gatowski, Gerald P. Ginsburg, Mara L. Merlino, Veronica Dahir, and James T. Richardson. 2001. "Surveying difficult populations: Lessons learned from a national survey of state trial court judges." The Justice System Journal 22(3):287-314.

Ehlers, Stephan, and Christopher Gillberg. 1993. "The epidemiology of Asperger syndrome." Journal of Child Psychology and Psychiatry 34(8):1327-1350. http://dx.doi.org/10.1111/j.1469-7610.1993.tb02094.x

Everall, Ian Paul, and Ann Lecouteur. 1990. "Firesetting in an adolescent boy with Asperger's syndrome." The British Journal of Psychiatry 157.2: 284-287. http://dx.doi.org/10.1192/bjp.157.2.284

Fowler, Floyd J., ed. 2009. Survey Research Methods. Vol. 1.Thousand Oaks, CA: Sage.

Frosch, Dan, and Kirk Johnson. July 20, 2012. "Gunman kills 12 in Colorado, reviving gun debate." The New York Times. Retrieved on January 14, 2014 (http://www.nytimes.com/ 2012/07/21/us/shooting-at-colorado-theater-showingbatman- movie.html?pagewanted=all).

Gaylin, Willard. 1974. Partial justice: A Study of Bias in Sentencing New York: Alfred A. Knopf.

Gerbner, George. 1980. "Dreams that hurt: mental illness in the mass media." Pp. 19-23 in The Community Imperative edited by Richard Baron, Irving Rutman and Barbara Klaczynska. Philadelphia, PA: Horizon House Institute.

Ghaziuddin, Mohommad, Luke Tsai, and Neera Ghaziuddin. 1991. "Brief report: violence in Asperger syndrome, a critique." Journal of Autism and Developmental Disorders 21(3): 349354. http://dx.doi.org/10.1007/BF02207331

Glaser, Barney G. and Anselm L. Strauss. 1967. The Discovery of Grounded Theory: Strategies for Qualitative Research. New York: Aldine De Gruyter.

Goffman, Erving. 1959. The moral career of the mental patient. Psychiatry 22(2):123-42.

Goffman, Erving. 1986. Stigma: Notes on the management of spoiled identity. New York: Simon \& Schuster.

Gunasekaran, Santhana, and Eddie Chaplin. 2012. "Autism spectrum disorders and offending." Advances in Mental Health and Intellectual Disabilities 6.6:308-313. http://dx.doi.org/10.1108/20441281211285955

Guthrie, Chris, Jeffrey J. Rachlinski, and Andrew J. Wistrich. 2000. "Inside the judicial mind." Cornell Law Review 86:777-830.

Guterbock, Thomas M., Brian J. Meekins, Alf C. Weaver, and John C. Fries. May 2000. "Web versus paper: A Mode experiment in a survey of university computing." Paper presented at the Annual Meeting of the American Association for Public Opinion Research, Portland, OR.

Hare, Dougal Julian, Judith Gould, Richard Mills, and Lorna Wing. 1999. "A preliminary study of individuals with autistic 
spectrum disorders in three special hospitals in England." London: National Autistic Society. Retrieved November 3, 2013 (http//www.aspires-relationships.com/ASPIRES/aspires/ASPIRES/3hospitals.pdf).

Harris, Louis. 1991. Public attitudes towards people with disabilities. New York: Louis Harris and Associates.

Haskins, Barbara G., and J. Arturo Silva. 2006. "Asperger's disorder and criminal behavior: forensic-psychiatric considerations." Journal of the American Academy of Psychiatry and the Law Online 34(3):374-384

Howlin, Patricia. 2004. Autism and Asperger Syndrome: Preparing for Adulthood. $2^{\text {nd }}$ ed. New York, NY: Routledge.

Institute of Medicine. 2006. Improving the Quality of Health Care for Mental and Substance-Use Conditions. Washington, DC: Institute of Medicine.

Kanuk, Leslie, and Conrad Berenson.1975."Mail surveys and response rates: A literature review." Journal of Marketing Research 12:440-453.

http://dx.doi.org/10.2307/3151093

Klin, Ami. 2006. "Autism and Asperger Syndrome: An Overview." Revista Brasileira de Psiquiatria 28:s3-s11. http://dx.doi.org/10.1590/S1516-44462006000500002

Lutz, Amy. December 17, 2012. "Don't Be Afraid of People With Autism." Slate. Retrieved on January 14, 2014 (http://www.slate.com/articles/health and science/medical e xaminer/2012/12/adam_lanza_asperger_s_can_autism_ explain_the_sandy_hook_tragedy.html).

Mawson, David C., Adrian Grounds, and Digby Tantam. 1985. "Violence and Asperger's syndrome: a case study." The British Journal of Psychiatry 147:566-569. http://dx.doi.org/10.1192/bjp.147.5.566

Mayes, Thomas A., and Robert L. Koegel. 2003. "Persons with Autism and Criminal Justice core concepts and leading cases." Journal of Positive Behavior Interventions 5.2:92100.

http://dx.doi.org/10.1177/10983007030050020401

Mental Health America. 1999. American Opinions on Mental Health Issues. Alexandria: National Mental Health Association.

Mouridsen, Svend Erik, Bente Rich, Torben Isager, and Niels Jørgen Nedergaard. 2008. "Pervasive Developmental Disorders and Criminal Behaviour A Case Control Study." International Journal of Offender Therapy and Comparative Criminology 52(2):196-205 http://dx.doi.org/10.1177/0306624X07302056

Murphy, David. 2003. "Admission and cognitive details of male patients diagnosed with Asperger's Syndrome detained in a Special Hospital: comparison with a schizophrenia and personality disorder sample." The Journal of Forensic Psychiatry 14.3:506-524.

Murrie, Daniel C., Janet I. Warren, Marianne Kristiansson, and Park E. Dietz. 2002. "Asperger's syndrome in forensic settings." International Journal of Forensic Mental Health 1(1):59- 70. http://dx.doi.org/10.1080/14999013.2002.10471161

Monahan, John. 1992. "Mental disorder and violent behavior: perceptions and evidence." American Psychologist 47.4:511521.

http://dx.doi.org/10.1037/0003-066X.47.4.511

Myers, Fiona. 2004. "On the Borderline?: People with Learning Disabilities And/or Autistic Spectrum Disorders in Secure, Forensic and Other Specialist Settings." Scottish Executive Social Research.

Nano, Stephanie. December 16, 2012. "Connecticut school shooting: Experts say no link between Asperger's, violence." Associated Press. Retrieved on January 14, 2014 (http://www.vivacolorado.com/ci_22199830/connecticutschool-shooting-experts-say-no-linkbetween?source=most_viewed).
Owings, Lisa. 2014. Newtown School Shooting. Minneapolis, MN: ABDO Publishing Company.

Parry, John W. "The Death Penalty and Persons with Mental Disabilities: A Lethal Dose of Stigma, Sanism, Fear of Violence, and Faulty Predictions of Dangerousness." 2005. Mental and physical disability law reporter 29(5):667-669.

Perlin, Michael L. and Ken K. Gould. 1995. "Rashomon and Criminal Law: Mental Disability and the Federal Sentencing Guidelines." American Journal of Criminal Law 22(431): 44243.

Plank, Alex. December 22, 2012. "Leave autism out of mass shootings." CNN. Retrieved on January 14, 2014 (http://www.cnn.com/2012/12/21/opinion/plank-autismnewtown/).

QSR International. 2012. NVivo Qualitative Analysis Software. QSR International Pty Ltd, Version 10.

Robert Wood Johnson Foundation. 1990. Public Attitudes Toward People with Chronic Mental Illness. The Robert Wood Johnson Foundation Program on Chronic Mental Illness, New Jersey.

Robinson, Peter. 2012. An Empirical Study of Settlement Conference Nuts and Bolts: Settlement Judges Facilitating Communication, Compromise and Fear. Harvard Negotiation Law Review 17:97-289.

Rochman, Bonnie. December 19, 2012. "Guilt by Association: Troubling Legacy of Sandy Hook May Be Backlash Against Children with Autism." TIME. Retrieved on January 14, 2014 (http://healthland.time.com/2012/12/19/guilt-by-associationtroubling-legacy-of-sandy-hook-may-be-backlash-againstchildren-with-autism/\#).

Rodriguez, Joe. December 24, 2012. "Asperger's sufferers fear Adam Lanza will become their poster boy." San Jose Mercury News. Retrieved on January 14, 2014 (http://www.mercurynews.com/ci_22255763/aspergerssufferers-fear-adam-lanza-will- become-their).

Scragg, Peter, and Amitta Shah. 1994. "Prevalence of Asperger's syndrome in a secure hospital." The British Journal of Psychiatry 165.5:679-682. http://dx.doi.org/10.1192/bjp.165.5.679

Sedensky, Stephen. December 14, 2012. Report of the State's Attorney for the Judicial District of Danbury on the Shootings at Sandy Hook Elementary School and 36 Yogananda Street, Newtown, Connecticut on December 14, 2012. Office of the State's Attorney Judicial District of Danbury. Retrieved on January 14, 2014 (http://www.ct.gov/csao/lib/csao/Sandy Hook_Final_Report.pdf).

Signorielli, Nancy. 1989. "The stigma of mental illness on television." Journal of Broadcasting and Electronic Media 33.3:325-331. http://dx.doi.org/10.1080/08838158909364085

Siponmaa, Leila, M. Kristiansson, Carin Jonson, Agneta Nyden, and Christopher Gillberg. 2001. "Juvenile and young adult mentally disordered offenders: the role of child neuropsychiatric disorders." Journal of the American Academy of Psychiatry and the Law Online 29(4):420-426.

Shain, Russell E., and Julie Phillips. 1991. "The stigma of mental illness: Labeling and stereotyping in the news." Pp. 61-74 in Risky Business: Communicating issues of science, risk, and public policy edited by Lillian Black Wilkins and Philip Paterson. Westport, CT: Greenwood Press.

Stewart, Carl E. 2003. "Abuse of Power and Judicial Misconduct: A Reflection on Contemporary Ethical Issues Facing Judges." University of St. Thomas Law Journal 1(1):Article 22.

Strauss, Anselm and Juliet M. Corbin. 1990. Basics of Qualitative Research: Grounded Theory Procedures and Techniques. Newbury Park, CA: Sage Publications.

Tantam, Digby. 1991. "Asperger syndrome in adulthood." Pp. 147183 in Autism and Asperger Syndrome, edited by Uta Frith. Cambridge: Cambridge University Press. 
Thompson, M. April 1984. Industrial Postal Surveys. Industrial Market Research Association Seminar, London. pp.1-9.

Ulmer, Jeffery T. 1994. "Trial Judges in Rural Community Courts: Contexts, Organizational Relations, and Interaction Strategies." Journal of Contemporary Ethnography 23(1):79108.

http://dx.doi.org/10.1177/089124194023001005

Wachtel, Lee E., and Edward Shorter. 2013. "Autism plus psychosis: A 'one-two punch'risk for tragic violence?." Medical Hypotheses 81(3):404-409. http://dx.doi.org/10.1016/j.mehy.2013.05.032

Wahl, Otto F. 1997. Media Madness: Public Images of Mental Illness. New Brunswick, NJ: Rutgers University Press.

Wahl, Otto F. 2003. "Depictions of mental illness in children's media." Journal of Mental Health UK 12:249-258. http://dx.doi.org/10.1080/0963823031000118230

Wahl, Otto F., and Rachel Roth. 1982. "Television images of mental illness: Results of a metropolitan Washington media watch." Journal of Broadcasting \& Electronic Media 26(2):599-605.

Watson, Amy, Patricia Hanrahan, Daniel Luchins, and ArthurLurigio. 2001. "Paths to jail among mentally ill persons: Service needs and service characteristics." Psychiatric Annals 31(7):421-429

Wessely, Simon. 2012. "Anders Breivik, the public, and psychiatry." The Lancet 379(9826): 1563-1564. http://dx.doi.org/10.1016/S0140-6736(12)60655-2
Whitehead, John C.1991. "Environmental Interest Group Behavior and Self-Selection Bias in Contingent Valuation Mail Surveys." Growth and Change 22(1):10-20. http://dx.doi.org/10.1111/j.1468-2257.1991.tb00538.x

Wilson, Claire, Raymond Nairn, John Coverdale, and Aroha Panapa 2000. "How mental illness is portrayed in children's television A prospective study." The British Journal of Psychiatry 176(5):440-443. http://dx.doi.org/10.1192/bjp.176.5.440

Wing, Lorna. 1981. "Asperger's syndrome: a clinical account." Psychological Medicine 11:115- 129. http://dx.doi.org/10.1017/S0033291700053332

Wing, Lorna. 1996. The Autistic Spectrum: A Guide for Parents and Professionals. London: Robinson.

Woodbury-Smith, M.R., I.C.H. Clare, A. J. Holland, and A. Kearns. 2006. "High functioning autistic spectrum disorders, offending and other law-breaking: findings from a community sample." The Journal of Forensic Psychiatry and Psychology 17(1):108-120. http://dx.doi.org/10.1080/14789940600589464

$\mathrm{Yu}$, Julie, and Harris Cooper. 1983. "A quantitative review of research design effects on response rates to questionnaires." Journal of Marketing Research 20:36-44. http://dx.doi.org/10.2307/3151410

Received on 08-11-2013

Accepted on 20-01-2014

Published on 05-02-2014

DOI: http://dx.doi.org/10.6000/1929-4409.2014.03.04

(C) 2014 Colleen M. Berryessa; Licensee Lifescience Global.

This is an open access article licensed under the terms of the Creative Commons Attribution Non-Commercial License (http://creativecommons.org/licenses/by-nc/3.0/) which permits unrestricted, non-commercial use, distribution and reproduction in any medium, provided the work is properly cited. 